\title{
Effect of fluid loading during hypovolaemic shock on caspofungin pharmacokinetic parameters in pig
}

Antoine Roch ${ }^{1,4^{*}}$, Christian Woloch ${ }^{2}$, Dorothée Blayac ${ }^{1,4}$, Caroline Solas ${ }^{2}$, Sylvie Quaranta $^{2}$, Vincent Mardelle ${ }^{3}$, Matthias Castanier ${ }^{1,4}$, Laurent Papazian ${ }^{1,4}$ and Emmanuelle Sampol-Manos ${ }^{2}$

\begin{abstract}
Introduction: Caspofungin treatment is frequently initiated in shock patients. In the present study, we investigated the influence of hypovolaemic shock requiring fluid loading on the plasma and pulmonary pharmacokinetic parameters of caspofungin in the pig.

Methods: After being anaesthetised and mechanically ventilated, 12 pigs were bled to induce a two-hour deep shock and resuscitated using normal saline based on haemodynamic goals. A one-hour infusion of $70 \mathrm{mg}$ of caspofungin was started at the beginning of the resuscitation period. The lungs were removed four hours after caspofungin administration. Sixteen animals served as controls without haemorrhage. Caspofungin concentrations were measured by using high-performance liquid chromatography, and a two-compartment population pharmacokinetic analysis was performed.

Results: In the shock group, the volume of blood removed was $39 \pm 7 \mathrm{~mL} / \mathrm{kg}$ and a volume of $90 \pm 17 \mathrm{~mL} / \mathrm{kg}$ saline was infused throughout the resuscitation period. The extravascular lung water index was higher in the shock group $(9.3 \pm 1.6 \mathrm{~mL} / \mathrm{kg}$ vs $5.7 \pm 1 \mathrm{~mL} / \mathrm{kg}$ in the control group; $P<0.01)$. In the shock group, the median (interquartile range) maximal plasma concentration was $37 \%$ lower than in the control group $(21.6 \mu \mathrm{g} / \mathrm{mL}(20.7$ to 22.3) vs $33.1 \mu \mathrm{g} / \mathrm{mL}$ (28.1 to 38.3); $P<0.01$ ). The median area under curve (AUC) from zero to four hours was $25 \%$ lower in the shock group than in the control group (60.3 hours $\times \mu \mathrm{g} / \mathrm{mL}$ (58.4 to 66.4) vs 80.8 hours $\times \mu \mathrm{g} / \mathrm{mL}$ (78.3 to 96.9$) ; P<0.01)$, as was the median lung caspofungin concentration $(1.22 \mu \mathrm{g} / \mathrm{g}(0.89$ to 1.46$) \mathrm{vs} 1.64 \mu \mathrm{g} / \mathrm{g}(1.22$ to 2.01); $P<0.01$ ). However, the plasma-to-tissue ratios were not different between the groups, indicating that lung diffusion of caspofungin was not affected after shock followed by fluid loading. Pharmacokinetic analysis showed that the peripheral volume of distribution of caspofungin and intercompartmental clearance were significantly higher in the shock group, as was the total apparent volume of distribution.

Conclusions: Hypovolaemic shock followed by fluid loading in the pig results in a significant increase in the apparent volume of distribution of caspofungin and in a decrease in its plasma and pulmonary exposition. Although our model was associated with capillary leakage and pulmonary oedema, our results should be generalised to the septic shock with caution. Future investigations should focus on monitoring plasma caspofungin concentrations and optimal caspofungin dosing in shock patients.
\end{abstract}

Keywords: echinocandin, pharmacokinetics, intensive care unit, lung

\footnotetext{
* Correspondence: antoine.roch@mail.ap-hm.fr

'Aix-Marseille Univ, URMITE CNRS-UMR 6236, 27 boulevard Jean Moulin,

13005 Marseille, France

Full list of author information is available at the end of the article
} 


\section{Introduction}

Fungal infections are an important cause of mortality in ICU patients [1]. Moreover, the prevalence of Candida infections has increased during the past decade or so [2], and recent data indicate that invasive pulmonary aspergillosis may be an underestimated opportunistic fungal infection in ICU patients [3].

Drug pharmacokinetic parameters in ICU patients are often different from those in healthy patients, notably because of physiological alterations induced by sepsis [4-6]. Besides changes in tissue perfusion, protein binding and clearance, the observed alterations in membrane permeability and the subsequently required fluid loading increase the volume of distribution of many drugs, which results in insufficient dosages of some antibiotics in a significant proportion of ICU patients [6-8].

Echinocandins such as caspofungin are semisynthetic lipopeptides with a pathogen-specific mechanism for noncompetitive inhibition of biosynthesis of the fungus cell wall enzyme complex 1,3- $\beta$-D-glucan $[9,10]$. Echinocandins have documented in vivo activity against Candida spp. [11] and Aspergillus spp. [12]. They are recognised as antifungal agents of choice in ICU patients [13]. The antifungal activity of echinocandins is concentration- and time-dependent and the ratio of area under the curve (AUC) to the minimal inhibitory concentration has been shown to be a good descriptor of their exposure-response relationship [14-16]. Therefore, the adequacy of the initial dose is an important point in the efficacy of echinocandins [17]. In the ICU, caspofungin treatment is frequently initiated in patients who present with septic shock, which is notably characterised by hypovolaemia requiring fluid loading for several hours. The exposition and distribution of caspofungin may be affected in these patients, resulting in insufficient plasma and tissue concentrations [18].

The selective study of the impact of hypovolaemic shock and fluid loading is difficult in ICU patients, who have many comorbidities that can affect caspofungin pharmacokinetics, such as renal insufficiency, need for dialysis, widely variable albumin levels and concomitant medications. For this reason, in the present study, we specifically investigated the influence of hypovolaemic shock followed by fluid loading on the plasma pharmacokinetic parameters and the pulmonary diffusion of caspofungin in a clinically relevant pig model. Our protocol was designed to mimic, with good reproducibility, deep hypovolaemic shock followed by resuscitation concomitantly with caspofungin administration.

\section{Materials and methods}

The study protocol was approved by the ethics committee of the Institut de médecine tropicale du service de santé des armées, Marseille, France. Twenty-eight four- month-old pigs weighing $40 \pm 3 \mathrm{~kg}$ (mean $\pm \mathrm{SD}$ ) were studied.

\section{Anaesthesia and monitoring}

Since inducing deep, sustained shock is inconsistent with spontaneous ventilation, the pigs were anaesthetised and mechanically ventilated. After premedication by intramuscular injection of $2 \mathrm{mg} / \mathrm{kg}$ midazolam, anaesthesia was induced and maintained by an intravenous infusion of midazolam $(0.2 \mathrm{mg} / \mathrm{kg} /$ hour $)$, fentanyl (0.01 mg/kg/hour) and pancuronium ( $0.3 \mathrm{mg} / \mathrm{kg} /$ hour $)$. A normal saline solution ( $3 \mathrm{~mL} / \mathrm{kg} /$ hour) was infused continuously throughout experiment. The animals were tracheotomised and ventilated with a tidal volume of 10 $\mathrm{mL} / \mathrm{kg}$ and a fraction of inspired oxygen of 0.5 (Servo 900C ventilator; Siemens-Elema AB, Solna, Sweden). The respiratory rate was adjusted to obtain an arterial partial pressure of carbon dioxide between 35 and 45 mmHg. A 5-French catheter (Edwards Lifesciences, Irvine, CA, USA) was inserted into the left internal jugular vein for fluid loading, and another 5-French catheter was inserted into the left carotid artery for blood withdrawal and monitoring of mean arterial pressure (MAP). A pulmonary artery catheter (Edwards Lifesciences) was inserted through the right external jugular vein into the right pulmonary artery for measurement of cardiac index $(\mathrm{CI})$. Identification of the $\mathrm{CI}$ end point during the haemorrhage and resuscitation periods was assessed using the Vigilance Continuous Cardiac Output Monitor (Baxter, Deerfield, IL, USA). CI values recorded for analysis were obtained after injection of three $12-\mathrm{mL}$ boluses of $5 \%$ glucose solution between $0^{\circ} \mathrm{C}$ and $5^{\circ} \mathrm{C}$ via a closed system at end inspiration. Mixed venous oxygen saturation $\left(\mathrm{SVO}_{2}\right)$ in pulmonary arterial blood was measured using a CO-oximeter (278 Blood Gas System; Ciba Corning, Medfield, MA, USA).

\section{Experimental groups}

In the shock group $(n=12)$, the animals were bled through the carotid catheter (Figure 1). Blood withdrawal was started at a rate of 0.8 to $1 \mathrm{~mL} / \mathrm{kg} /$ minute and continued until all three of the following end points were achieved: MAP of 40 to $45 \mathrm{mmHg}$, decrease in CI greater than $40 \%$ and $\mathrm{SVO}_{2}$ lower than $30 \%$. End points were maintained for a period of 120 minutes by means of further bleeding. During the four-hour resuscitation period, the animals received isotonic saline at a rate of 2 $\mathrm{mL} / \mathrm{kg} /$ minute. The infusions were stopped when the CI reached $90 \%$ of the baseline value and $\mathrm{SVO}_{2}$ was above $50 \%$, and the infusions were then adjusted to keep these parameters constant until the animals were killed. At the beginning of the resuscitation period, the animals received a one-hour intravenous infusion of $70 \mathrm{mg}$ of caspofungin acetate (Cancidas; Merck Sharp \& Dohme- 


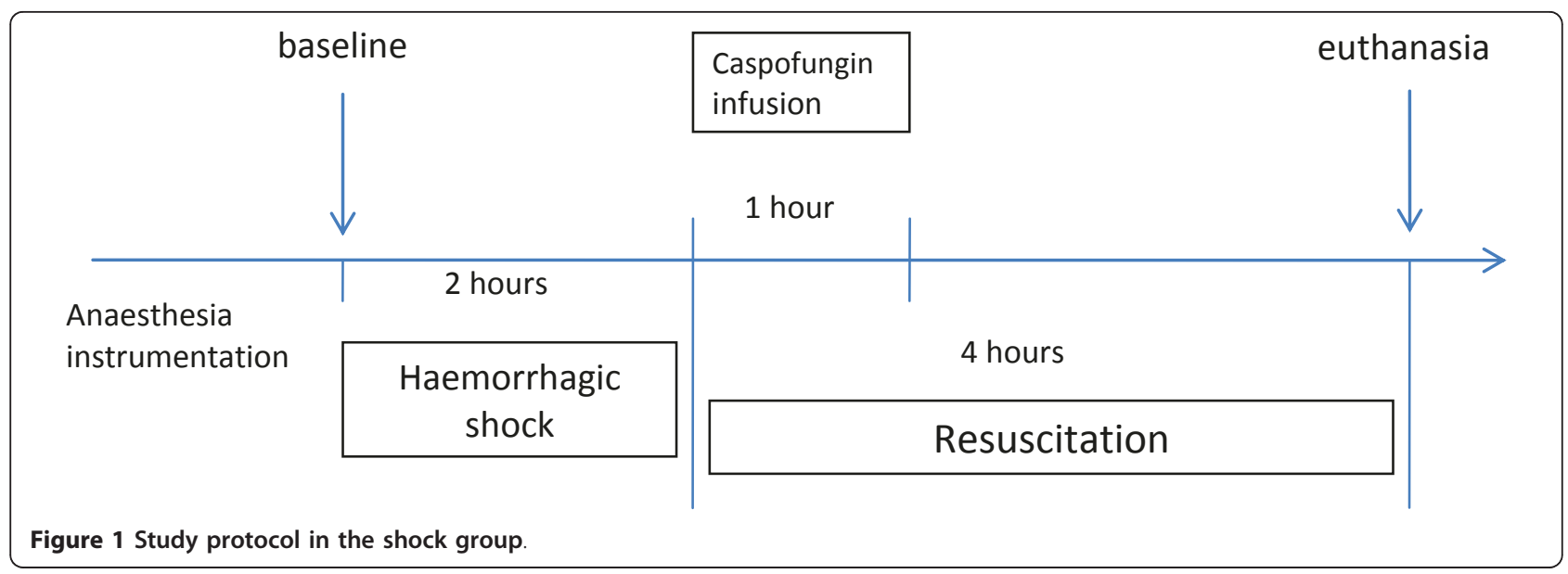

Chibret, Paris, France) diluted in $50 \mathrm{~mL}$ of saline, which was injected into the right atrium through the proximal lumen of the pulmonary arterial catheter via a pumpdriven syringe. A second group of animals $(n=16)$ used as controls was anaesthetised and ventilated, but they were not subjected to bleeding and fluid loading. These animals were also killed four hours after the start of the caspofungin infusion.

\section{Caspofungin sampling and assay}

EDTA-blood samples were drawn through a dedicated arterial catheter just before and 15, 30, 60 and 90 minutes and 2 hours, 3 hours and 4 hours after the caspofungin infusions were started in both groups. Then the animals were immediately killed, and lung tissue samples $(2 \mathrm{~cm} \times 2 \mathrm{~cm} \times 2 \mathrm{~cm})$ were surgically removed from nondependent parts of both the lower and upper lobes after sternotomy. Plasma was obtained by blood centrifugation at $1,500 \mathrm{~g}$ for 15 minutes. Plasma and lung samples were immediately stored at $-80^{\circ} \mathrm{C}$. The remaining lung tissues were used for the determination of extravascular lung water indexed to body weight (EVLWI) by using a gravimetric method as previously described [19]. Caspofungin acetate was kindly provided by Merck Sharp \& Dohme-Chibret. Plasma and lung caspofungin concentrations were determined by using a validated high-performance liquid chromatography method with fluorescence detection [20] after a solidphase extraction (Bond Elut ${ }^{\mathrm{TM}}$ column; Agilent Technologies, Santa Clara, CA, USA). Caspofungin and the internal standard (IS) propranolol were separated on a LiChrospher column (100 RP-8e $(5 \mu \mathrm{m})$; Merck Chemicals KGaA, Darmstadt, Germany) using a mobile phase consisting of acetonitrile and $0.1 \%$ trifluoroacetic acid buffer $(200: 300 \mathrm{vol} / \mathrm{vol})$ at a flow rate of $1 \mathrm{~mL} /$ minute. The retention times were 6 and 22 minutes for IS and caspofungin, respectively. The linearity range was 0.3 to $7.5 \mathrm{mg} / \mathrm{L}\left(r^{2}>0.998\right)$. The lower limit of quantification, defined as the lowest concentration that could be determined with a relative error and precision (relative standard deviation) less than $20 \%$, was $0.3 \mu \mathrm{g} / \mathrm{mL}$. Intraday and interday levels of interassay precision were $1.91 \%$ and $4.84 \%(0.5 \mu \mathrm{g} / \mathrm{mL}), 6.94 \%$ and $10.4 \%(3 \mu \mathrm{g} / \mathrm{mL})$ and $7.84 \%$ and $12 \%(5 \mu \mathrm{g} / \mathrm{mL})$ for serum samples. The maximal concentration $\left(C_{\max }\right)$ was measured at the end of the infusion.

Lung samples were weighed (200 $\pm 150 \mathrm{mg})$, homogenised with a $1.5-\mathrm{mL}$ saline solution, ground for $15 \mathrm{~min}$ utes and centrifuged twice at 10,000 rpm for 10 minutes. The supernatant liquid was separated, and then the IS solution was added to $1 \mathrm{~mL}$ of supernatant liquid. For calibration, we spiked different caspofungin and IS concentrations in saline (matrix of pretreatment). Lung caspofungin concentrations $\left(C_{t}\right)$ were determined four hours after starting the caspofungin infusion and are expressed as micrograms per gram of lung tissue. The tissue-to-plasma ratio for each group was calculated as $R=\left(C_{\mathrm{t}} / C_{\mathrm{p}}\right) \times 100$, where $C_{\mathrm{p}}$ is the caspofungin plasma concentration at four hours.

\section{Caspofungin pharmacokinetic analysis}

The AUC from zero to four hours $\left(\mathrm{AUC}_{0 \rightarrow 4}\right.$ hours $)$ was determined using the trapezoidal rule. The concentration vs time data for both groups were modelled using the population approach method implemented in Monolix version 3.1 release 2 software. A two-compartment mammillary model was developed and parameterised in terms of central volume of distribution of caspofungin $\left(V_{1}\right)$ and elimination clearance of caspofungin (CL), peripheral volume of distribution of caspofungin $\left(V_{2}\right)$ and intercompartmental clearance of caspofungin $(\mathrm{Q})$. The total apparent volume of distribution of caspofungin $\left(V_{\mathrm{d}}\right)$ was calculated as $V_{1}+V_{2}$. The interindividual variability $(\omega)$ for each parameter and the residual variability of the model $(\sigma)$ were estimated. 


\section{Statistical analysis}

Statistical calculations were performed using the SPSS 15.0 software package (SPSS Inc., Chicago, IL, USA). The results are expressed as means \pm standard deviations (SD) if data were normally distributed or as medians (interquartile ranges). Two-way analysis of variance for repeated measures was used to analyse the effect of group and time on MAP. Tukey's test was used for post hoc analyses. The Mann-Whitney rank-sum test was used to compare plasma caspofungin concentrations, $\operatorname{AUC}_{0 \rightarrow 4}$ hours, lung caspofungin concentrations $\left(C_{\mathrm{t}}\right)$, plasma-to-tissue ratios and caspofungin population pharmacokinetic parameters between groups. $P \leq 0.05$ was considered statistically significant.

\section{Results}

Haemodynamics and lung water

In the shock group, the volume of blood removed was $39 \pm 7 \mathrm{~mL} / \mathrm{kg}$, and a volume of $90 \pm 17 \mathrm{~mL} / \mathrm{kg}$ of isotonic saline was infused throughout the resuscitation period (Figure 2). MAP was progressively restored during fluid loading and was not different from the control group from three hours of resuscitation (Figure 3). EVLWI was higher in the shock group than in the control group $(9.3 \pm 1.6 \mathrm{~mL} / \mathrm{kg}$ vs $5.7 \pm 1 \mathrm{~mL} / \mathrm{kg} ; P<0.01)$.

\section{Caspofungin plasma pharmacokinetics}

The caspofungin plasma concentration profile over a four-hour period in animals in the shock and control groups is presented in Figure 4. Median $C_{\max }$ was $35 \%$ lower in the shock group $(P<0.002$ vs control group) (Figure 4 and Table 1), and the caspofungin concentration remained significantly lower in the shock group until four hours after caspofungin infusion was started, resulting in a $25 \%$ lower median $\mathrm{AUC}_{0 \rightarrow 4}$ hours (Table $1)$. Whereas $V_{1}$ and $\mathrm{CL}$ from the central compartment were not different between groups, $\mathrm{Q}, V_{2}$ and $V_{\mathrm{d}}$ were higher in the shock group (Table 2).

\section{Lung caspofungin concentrations}

Caspofungin concentrations were not significantly different between the lower and upper lung lobes or between the left and right lungs. Therefore, values from the four sampled lobes were averaged, and the mean lung concentration is reported. We observed a $25 \%$ lower median lung caspofungin concentration in the shock group than in the control group (Table 1). However, no significant difference was observed between plasma-to-tissue ratios in the two groups, indicating that lung diffusion of caspofungin was not affected after shock followed by fluid loading.

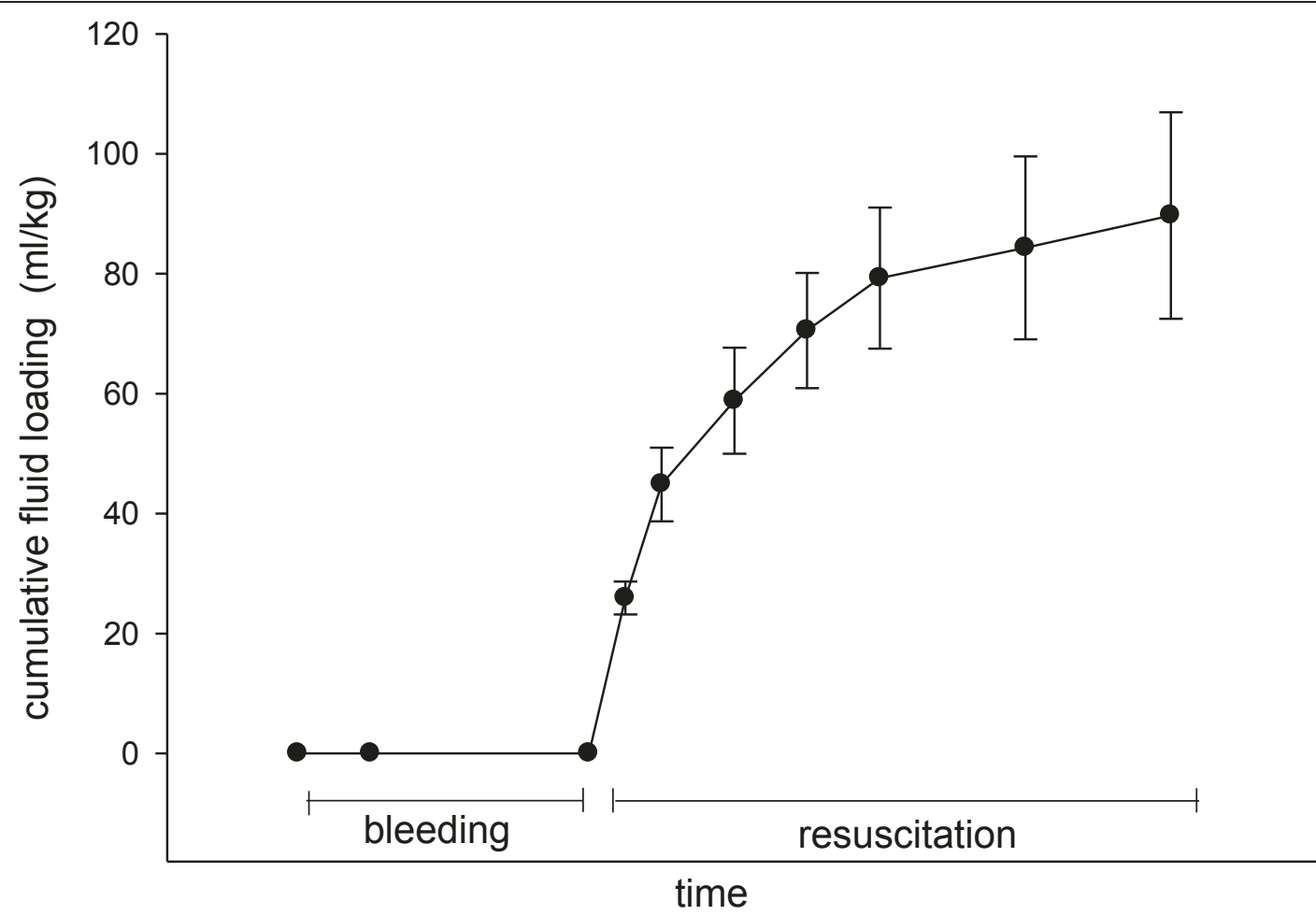

Figure 2 Time evolution of cumulative fluid loading in the shock group. The results are expressed as means \pm standard deviation (SD). 


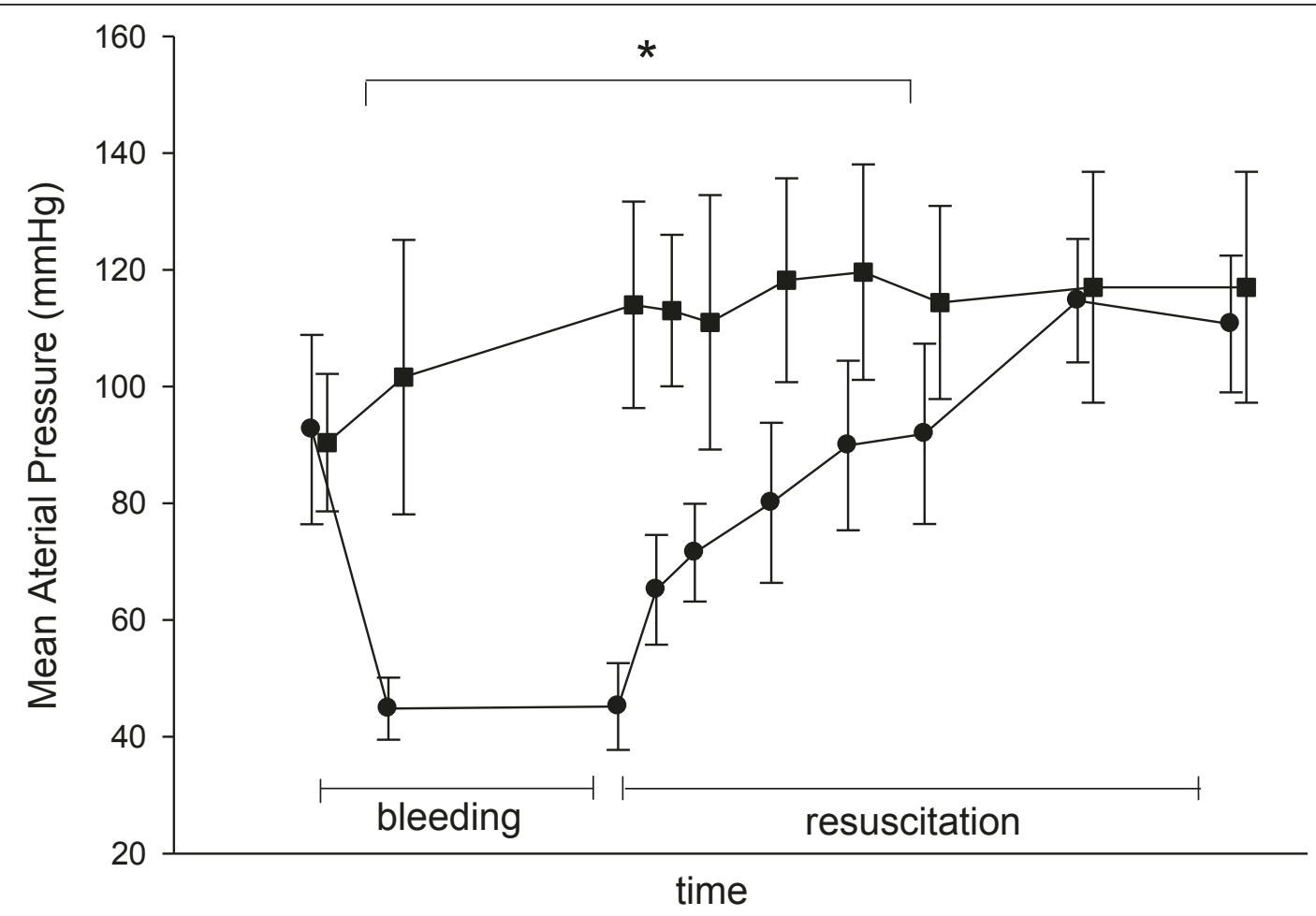

Figure 3 Mean arterial pressure in the control group (squares) and shock group (circles) at baseline and after 30 minutes and 120 minutes of bleeding, as well as after 15, 30, 60, 90 and 120 minutes of resuscitation and after 3 and 4 hours of resuscitation. The results are expressed as means \pm standard deviation (SD). ${ }^{*} P<0.001$ between groups (Tukey's test).

\section{Discussion}

In ICU patients, septic shock is common and carries a high mortality rate [21]. In this situation, both the precocity and adequacy of antimicrobial therapy are major prognostic factors [22]. The antifungal activity of caspofungin has been shown to be concentration-dependent in vitro and in vivo $[14,15]$. Moreover, the adequacy of the initial dose may be an important point in the efficacy of echinocandins [17]. Therefore, it is critical to administer a sufficient dose, especially in the first days of treatment. Our results show that hypovolaemic shock followed by fluid loading in the pig results in a significant decrease in early plasma caspofungin exposition, as reflected by a lower maximal concentration and a lower $\mathrm{AUC}_{0 \rightarrow 4}$ hours. Fluid loading was associated with a decrease in the pulmonary concentration of caspofungin.

In the early clinical development program for caspofungin, a target concentration of $1 \mu \mathrm{g} / \mathrm{mL}$ was used as a guide for concentrations likely to be efficacious. This target was determined on the basis of in vitro susceptibility test results and was selected as the concentration that exceeded the minimal inhibitory concentration at which 90\% of Candida spp. isolates were inhibited [23]. In healthy humans, a single dose of $70 \mathrm{mg}$ resulted in a mean plasma $C_{\max }$ of $12.04 \mu \mathrm{g} / \mathrm{mL}$ ( $95 \%$ confidence interval, 10.87 to 13.33 ) and a concentration at 24 hours (trough concentration) of $1.42 \mu \mathrm{g} / \mathrm{mL}$ (95\% confidence interval, 1.18 to 1.71 ) with linear plasma pharmacokinetics [24]. On the basis of these studies, a once-daily dosing regimen of $50 \mathrm{mg}$ was considered adequate for efficacy in the treatment of fungal infections. However, a loading dose of $70 \mathrm{mg}$ is recommended, since trough caspofungin plasma concentrations fell below the target concentration of $1 \mu \mathrm{g} / \mathrm{mL}$ for the first two days of administration in the absence of a loading dose.

The pharmacokinetics of caspofungin have been recently studied in a cohort of surgical ICU patients [18]. In that study, caspofungin exhibited wide variations in 24-hour trough plasma concentrations during the whole treatment period. Although the mean trough concentration at day 2 of treatment was slightly higher than reported in healthy humans [21] and exceeded $1.0 \mu \mathrm{g} /$ $\mathrm{mL}$ in $75 \%$ of patients, it failed to reach this target concentration in $25 \%$ of them [18]. Therefore, the authors concluded that a dose adjustment may be necessary in some ICU patients, based on the monitoring of plasma concentrations. Although 29 of the 40 included patients received vasopressors for shock, neither the need for fluid loading nor its impact on caspofungin pharmacokinetics was reported [18]. The authors attributed the variability of caspofungin pharmacokinetics not only to the effect of supportive therapies such as fluid loading, 


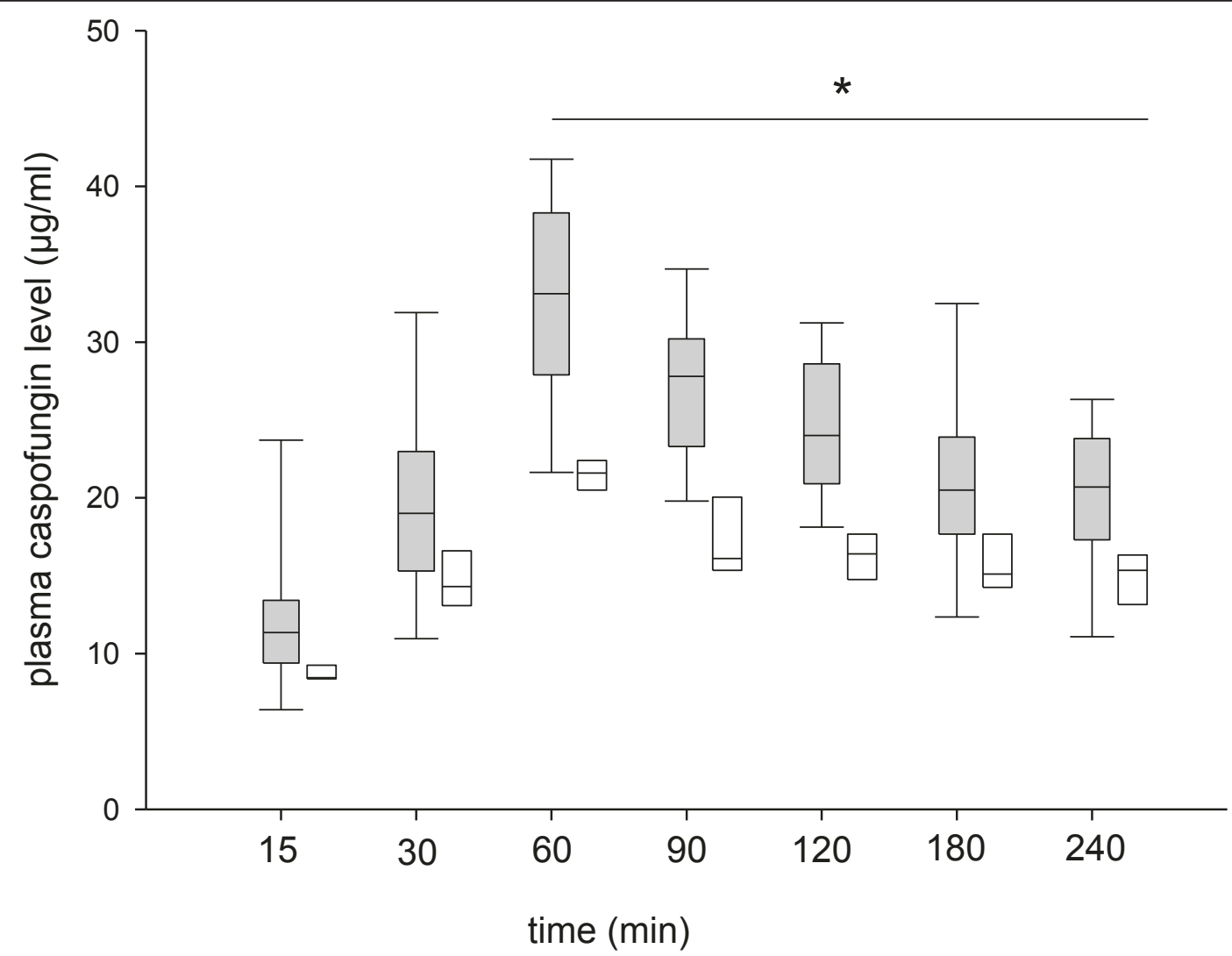

Figure 4 Caspofungin concentration time profile in the shock group (white plots) and in the control group (grey plots). Each plot represents the median and 25 th and 75 th percentile values. Bars represent the 5th and 95th percentiles. ${ }^{*} P<0.01$ vs control group.

haemodialysis and catecholamines but also to patientspecific parameters such as albuminaemia, organ dysfunction and weight. In the present study, we specifically evaluated the effect of hypovolaemic shock requiring large fluid loading with a positive fluid balance exceeding $50 \mathrm{~mL} / \mathrm{kg}$. Our observed decrease in plasma and pulmonary caspofungin exposition in this situation points out that this factor may largely contribute to the underdosing reported in ICU patients [18]. Since the volume of distribution of echinocandins is likely to correspond to the extracellular volume [25], the massive fluid loading required to restore and maintain haemodynamics observed in the present study or in shock patients in general is likely to be responsible for the increase in $V_{2}$ and $V_{\mathrm{d}}$ as well as in the subsequent decrease in caspofungin's early plasma and tissue concentrations. Whether a subsequent modification of $\mathrm{CL}$ would affect its pharmacokinetics in this situation requires further studies. Notably, the haemodynamic failure observed while initiating treatments such as

Table 1 Caspofungin pharmacokinetic parameters in plasma and lung tissue

\begin{tabular}{|c|c|c|c|c|c|}
\hline \multirow[b]{2}{*}{ Caspofungin parameters } & \multicolumn{2}{|c|}{ Shock group $(n=12)$} & \multicolumn{2}{|c|}{ Control group $(n=16)$} & \multirow[b]{2}{*}{$P$ value } \\
\hline & Median & IQR & Median & IQR & \\
\hline \multicolumn{6}{|l|}{ Plasma } \\
\hline$C_{\max }(\mu \mathrm{g} / \mathrm{mL})$ & 21.6 & 20.7 to 22.3 & 33.1 & 28.1 to 38.3 & 0.002 \\
\hline $\mathrm{AUC}_{0 \rightarrow 4}$ hours $(\mu \mathrm{g} / \mathrm{hour} / \mathrm{mL})$ & 60.3 & 58.4 to 66.4 & 80.8 & 78.3 to 96.9 & 0.009 \\
\hline$C_{p}(\mu g / m L)$ & 16.1 & 12.5 to 17.4 & 20.7 & 17.4 to 23.1 & 0.007 \\
\hline \multicolumn{6}{|l|}{ Lung tissue } \\
\hline$C_{t}(\mu g / g)$ & 1.22 & 0.89 to 1.46 & 1.64 & 1.22 to 2.01 & 0.001 \\
\hline Ratio (\%) & 7.76 & 6.41 to 9.42 & 7.28 & 6.2 to 9.5 & 0.862 \\
\hline
\end{tabular}

AUC $_{0 \rightarrow 4}$ hours: area under the curve of caspofungin plasma concentration from zero to four hours; $C_{\text {max }}$ maximum caspofungin concentration; $C_{\mathrm{p}}$ : caspofungin plasma concentration at four hours; $C_{\mathrm{t}}$ : lung caspofungin concentration at four hours; IQR: interquartile range. Ratio $=\left(C_{\mathrm{t}} / C_{\mathrm{p}}\right) \times 100 ; P$ values are for shock group vs control group. 
Table 2 Caspofungin population pharmacokinetic parameters in plasma

\begin{tabular}{lcccc}
\hline & \multicolumn{2}{c}{$\begin{array}{c}\text { Shock group } \\
(\boldsymbol{n}=\mathbf{1 2})\end{array}$} & \multicolumn{2}{c}{$\begin{array}{c}\text { Control group } \\
(\boldsymbol{n}=\mathbf{1 6})\end{array}$} \\
Caspofungin parameters & Estimate & RSE (\%) & Estimate & RSE (\%) \\
\hline $\mathrm{CL}(\mathrm{L} /$ hour $)$ & 0.21 & 26 & 0.29 & 20 \\
$V_{1}(\mathrm{~L})$ & 0.96 & 45 & 0.98 & 24 \\
$\mathrm{Q}(\mathrm{L} /$ hour $)$ & $8.16^{*}$ & 39 & 4.23 & 30 \\
$V_{2}(\mathrm{~L})$ & $2.8^{*}$ & 15 & 1.43 & 12 \\
$V d(\mathrm{~L})$ & $3.9^{*}$ & - & 2.5 & - \\
$\omega(\mathrm{CL})(\%)$ & 25 & 21 & 75 & 39 \\
$\omega\left(V_{1}\right)(\%)$ & 10 & 37 & 80 & 36 \\
$\omega(\mathrm{Q})(\%)$ & 10 & 32 & 54 & 35 \\
$\omega\left(V_{2}\right)(\%)$ & 10 & 35 & 19 & 34 \\
$\sigma(\%)$ & 28 & 13 & 34 & 8 \\
\hline
\end{tabular}

CL: central elimination clearance; Q: intercompartmental clearance; RSE: relative standard error:

$V_{1}$ : central volume of distribution; $V_{2}$ : peripheral volume of distribution; $V_{\mathrm{d}}$ : total apparent volume of distribution; $\sigma$ : residual variability of the model; $\omega$ : interindividual variability. ${ }^{*} P<0.05$ vs control group.

caspofungin in septic patients is frequently even more marked than in our present study [26]. Therefore, it is possible that caspofungin concentrations during the first days of treatment may be insufficient in a significant number of ICU patients with marked haemodynamic instability $[18,27]$.

With regard to lung tissue concentrations, our observed decrease in plasma concentration had a direct impact on pulmonary concentrations measured four hours after administration. These data signify that insufficient initial plasma concentrations may result in lowered concentrations at the site of the infection. As is true during sepsis, our model was characterised by lung oedema and inflammation [19], which did not affect the pulmonary diffusion of caspofungin or influence its distribution to the different lung lobes.

Our study has several limitations. First, we used a haemorrhagic shock model rather than an invasive fungal infection model. Animal models of invasive candidiasis or aspergillosis [28] are mainly used to study the efficacy of antifungal therapies. However, these models do not induce hypovolaemic shock such as required for the present study. A commonly used model of sepsis is lipopolysaccharide (LPS) injection [29], which reproduces bacterial sepsis. This model may be more representative than haemorrhagic shock of the capillary leakage observed during human sepsis and could have different influences on the distribution of caspofungin. However, this model has unpredictable effects on pharmacokinetics, since haemodynamic effects are very variable and pathophysiological changes caused by LPS administration can potentially affect all aspects of drug metabolism [29]. Moreover, our model is also characterised by capillary leakage and vascular failure, as attested by requirements for fluid loading and the observed increase in lung water. Second, we did not study the long-term pharmacokinetics of caspofungin, since our model is inconsistent with a prolonged survival of the animals without other therapeutic interventions. Considering the pharmacokinetic linearity of caspofungin [24], the decrease in caspofungin concentrations that we observed is likely to affect trough plasma and tissue concentrations. However, further studies are required to clarify whether tissue concentrations may be lowered during the course of several days. Indeed, therapeutic concentrations of caspofungin have been shown to persist at the site of infection well after serum concentrations fall below the minimal inhibitory concentration, and the terminal half-life of this drug has been suggested to be heavily influenced by the accumulation of caspofungin in tissues [28]. Third, we did not study which dose of caspofungin would result in similar exposition in shock and control animals. Recently, the use of higher caspofungin doses has been shown to be safe in healthy adults and could be evaluated in ICU patients [30]. Finally, we did not measure caspofungin concentrations in other tissues. However, lung concentrations of caspofungin are representative of those measured in various organs [31].

\section{Conclusions}

The present study shows that hypovolaemic shock requiring a massive fluid loading is responsible for a marked decrease in plasma and pulmonary caspofungin early exposition. Although our results are insufficient to recommend higher caspofungin doses in septic shock patients, they warrant for clinical studies to define the optimal dosing of caspofungin at the initial stage of fungal sepsis and to assess the usefulness of its concentration monitoring.

\section{Key messages}

- Hypovolaemic shock requiring massive fluid loading is responsible for a marked decrease in plasma and pulmonary caspofungin early exposition.

- Lung diffusion of caspofungin was not affected in these conditions.

- Investigators in future studies should study the optimal dosing of caspofungin at the initial stage of fungal sepsis and the usefulness of monitoring its concentration.

\section{Abbreviations}

ఠ: residual variability of the model; $\omega$ : interindividual variability; $A \cup C_{0 \rightarrow 4}$ hours: area under the curve of caspofungin plasma concentration from zero to four hours; Cl: cardiac index; CL: elimination clearance of caspofungin; $C_{\text {max: }}$ : maximal plasma concentration of caspofungin; $C_{\mathrm{p}}$ : caspofungin plasma concentration at four hours; $C_{\mathrm{t}}$ : lung caspofungin concentration at four hours; EVLWI: extravascular lung water indexed to body weight; MAP: mean 
arterial pressure; Q: intercompartmental clearance of caspofungin; $\mathrm{SVO}_{2}$ mixed venous oxygen saturation; $V_{1}$ : central volume of distribution of caspofungin; $V_{2}$ : peripheral volume of distribution of caspofungin; $V_{d}$ : total apparent volume of distribution of caspofungin.

\section{Acknowledgements}

We thank Mr Christian Aglioni, Mr William Menini and the Institut de médecine tropicale du service de santé des armées for technical support. This work was supported by the Institut de médecine tropicale du service de santé des armées, Marseille, France, and by a grant from Merck Sharp \& Dohme-Chibret (MSD), Paris, France. This grant was used for animal purchase and caspofungin dosing. The authors were totally independent from MSD and had full control of all primary data.

\section{Author details}

'Aix-Marseille Univ, URMITE CNRS-UMR 6236, 27 boulevard Jean Moulin, 13005 Marseille, France. ${ }^{2}$ Laboratoire de Pharmacocinétique et de Toxicologie, Hôpital de la Timone, 264 rue Saint Pierre, 13005, Marseille, France. ${ }^{3}$ Institut de médecine tropicale du service de santé des armées, 58 boulevard Charles Livon, 13007, Marseille, France. ${ }^{4}$ APHM, Hôpital Nord, Réanimation, Chemin des Bourrely 13915, Marseille, France.

\section{Authors' contributions}

AR and ES conceived the study, participated in coordination and drafted the manuscript. CW, DB, VM and MC collected data and helped to draft the manuscript. CS and SQ participated in coordination and drafted manuscript. LP participated in the design of the study and helped to draft the manuscript. All authors read and approved the final manuscript.

\section{Competing interests}

The authors declare that they have no competing interests.

Received: 4 May 2011 Revised: 20 June 2011

Accepted: 20 September 2011 Published: 20 September 2011

\section{References}

1. Leroy O, Gangneux JP, Montravers P, Mira JP, Gouin F, Sollet JP, Carlet J, Reynes J, Rosenheim M, Regnier B, Lortholary O, AmarCand Study Group: Epidemiology, management, and risk factors for death of invasive Candida infections in critical care: a multicenter, prospective, observational study in France (2005-2006). Crit Care Med 2009, 37:1612-1618.

2. Bassetti M, Righi E, Costa A, Fasce R, Molinari MP, Rosso R, Pallavicini FB, Viscoli C: Epidemiological trends in nosocomial candidemia in intensive care. BMC Infect Dis 2006, 6:21.

3. Trof RJ, Beishuizen A, Debets-Ossenkopp YJ, Girbes AR, Groeneveld AB: Management of invasive pulmonary aspergillosis in non-neutropenic critically ill patients. Intensive Care Med 2007, 33:1694-1703.

4. Cook AM: Pharmacokinetic alterations of antimicrobials in the critically ill. J Pharm Pract 2005, 18:75-83.

5. Pea F, Viale P, Furlanut M: Antimicrobial therapy in critically ill patients: a review of pathophysiological conditions responsible for altered disposition and pharmacokinetic variability. Clin Pharmacokinet 2005, 44:1009-1034.

6. De Paepe P, Belpaire FM, Buylaert WA: Pharmacokinetic and pharmacodynamic considerations when treating patients with sepsis and septic shock. Clin Pharmacokinet 2002, 41:1135-1151.

7. Belzberg H, Zhu J, Cornwell EE, Murray JA, Sava J, Salim A, Velmahos GC, Gill MA: Imipenem levels are not predictable in the critically ill patient. J Trauma 2004, 56:111-117.

8. Triginer C, Izquierdo I, Fernández R, Rello J, Torrent J, Benito S, Net A: Gentamicin volume of distribution in critically ill septic patients. Intensive Care Med 1990, 16:303-306.

9. Bouffard FA, Zambias RA, Dropinski JF, Balkovec JM, Hammond ML, Abruzzo GK, Bartizal KF, Marrinan JA, Kurtz MB, McFadden DC, Nollstadt KH, Powles MA, Schmatz DM: Synthesis and antifungal activity of novel cationic pneumocandin Bo derivatives. J Med Chem 1994, 37:222-225.

10. Kurtz MB, Heath IB, Marrinan J, Dreikorn S, Onishi J, Douglas C: Morphological effects of pneumocandins against Aspergillus fumigatus correlate with activity against (1,3)- $\beta$-D-glucan synthase. Antimicrob Agents Chemother 1994, 38:1480-1489.
11. Mora-Duarte J, Betts C, Rotstein A, Colombo AL, Thompson-Moya L, Smietana J, Lupinacci R, Sable C, Kartsonis N, Perfect J, Caspofungin Invasive Candidiasis Study Group: Comparison of caspofungin and amphotericin B for invasive candidiasis. N Engl J Med 2002, 347:2020-2029.

12. Maertens J, Glasmacher A, Herbrecht R, Thiebaut A, Cordonnier C, Segal BH, Killar J, Taylor A, Kartsonis N, Patterson TF, Aoun M, Caillot D, Sable C, Caspofungin Combination Therapy Study Group: Multicenter, noncomparative study of caspofungin in combination with other antifungals as salvage therapy in adults with invasive aspergillosis. Cancer 2006, 107:2888-2897.

13. Méan M, Marchetti O, Calandra T: Bench to bedside review: Candida infections in the intensive care unit. Crit Care 2008, 12:204.

14. van Vianen W, de Marie S, ten Kate MT, Mathot RA, Bakker-Woudenberg IA: Caspofungin: antifungal activity in vitro, pharmacokinetics, and effects on fungal load and animal survival in neutropenic rats with invasive pulmonary aspergillosis. J Antimicrob Chemother 2006, 57:732-740.

15. Wiederhold NP, Kontoyiannis DP, Chi J, Prince RA, Tam VH, Lewis RE: Pharmacodynamics of caspofungin in a murine model of invasive pulmonary aspergillosis: evidence of concentration-dependent activity. J Infect Dis 2004, 190:1464-1471.

16. Andes D, Diekema DJ, Pfaller MA, Bohrmuller J, Marchillo K, Lepak A: In vivo comparison of the pharmacodynamic targets for echinocandin drugs against Candida species. Antimicrob Agents Chemother 2010, 54:2497-2506.

17. Ota Y, Tatsuno K, Okugawa S, Yanagimoto S, Kitazawa T, Fukushima A, Tsukada K, Koike K: Relationship between the initial dose of micafungin and its efficacy in patients with candidemia. J Infect Chemother 2007, 13:208-212.

18. Nguyen T, Hoppe-Tichy T, Geiss HK, Rastall AC, Swoboda S, Schmidt J, Weigand MA: Factors influencing caspofungin plasma concentrations in patients of a surgical intensive care unit. J Antimicrob Chemother 2007, 60:100-106.

19. Roch A, Blayac D, Ramiara $P$, Chetaille B, Marin V, Michelet $P$, Lambert $D$, Papazian L, Auffray JP, Carpentier JP: Comparison of lung injury after normal or small volume optimized resuscitation in a model of hemorrhagic shock. Intensive Care Med 2007, 33:1645-1654.

20. Schwartz M, Kline W, Matuszewski B: Determination of a cyclic hexapeptide (L-743872), a novel pneumocandin antifungal agent in human plasma and urine by high-performance liquid chromatography with fluorescence detection. Anal Chim Acta 1997, 352:299-307.

21. Annane D, Aegertner $P$, Jars-Guincestre MC, Guidet B, CUB-Réa Network: Current epidemiology of septic shock: the CUB-Réa Network. Am J Respir Crit Care Med 2003, 168:165-172.

22. Kumar A, Roberts $D$, Wood KE, Light $B$, Parrillo JE, Sharma S, Suppes $R$, Feinstein D, Zanotti S, Taiberg L, Gurka D, Kumar A, Cheang M: Duration of hypotension before initiation of effective antimicrobial therapy is the critical determinant of survival in human septic shock. Crit Care Med 2006, 34:1589-1596.

23. Bartizal K, Gill CJ, Abruzzo GK, Flattery AM, Kong L, Scott PM, Smith JG, Leighton CE, Bouffard A, Dropinski JF, Balkovec J: In vitro preclinical evaluation studies with the echinocandin antifungal MK-0991 (L743,872). Antimicrob Agents Chemother 1997, 41:2326-2332.

24. Stone JA, Holland SD, Wickersham PJ, Sterrett A, Schwartz M, Bonfiglio C, Hesney M, Winchell GA, Deutsch PJ, Greenberg H, Hunt TL, Waldman SA: Single- and multiple-dose pharmacokinetics of caspofungin in healthy men. Antimicrob Agents Chemother 2002, 46:739-745.

25. Theuretzbacher U: Pharmacokinetics/pharmacodynamics of echinocandins. Eur J Clin Microbiol Infect Dis 2004, 23:805-812.

26. Rivers E, Nguyen B, Havstad S, Ressler J, Muzzin A, Knoblich B, Peterson E, Tomlanovich M, Early Goal-Directed Therapy Collaborative Group: Early goal-directed therapy in the treatment of severe sepsis and septic shock. N Engl J Med 2001, 345:1368-1377.

27. Gumbo T: Impact of pharmacodynamics and pharmacokinetics on echinocandin dosing strategies. Curr Opin Infect Dis 2007, 20:587-591.

28. Louie A, Deziel M, Liu W, Drusano MF, Gumbo T, Drusano GL: Pharmacodynamics of caspofungin in a murine model of systemic candidiasis: importance of persistence of caspofungin in tissues to understanding drug activity. Antimicrob Agents Chemother 2005, 49:5058-5068

29. Poli-de-Figueiredo LF, Garrido AG, Nakagawa N, Sannomiya P: Experimental models of sepsis and their clinical relevance. Shock 2008, 30(Suppl 1):53-59. 
30. Migoya EM, Mistry GC, Stone JA, Comisar W, Sun P, Norcross A, Bi S, Winchell GA, Ghosh K, Uemera N, Deutsch PJ, Wagner JA: Safety and pharmacokinetics of higher doses of caspofungin in healthy adult participants. J Clin Pharmacol 2011, 51:202-211.

31. Stone JA, Xu X, Winchell GA, Deutsch PJ, Pearson PG, Migoya EM, Mistry GC, Xi L, Miller A, Sandhu P, Singh R, deLuna F, Dilzer SC, Lasseter KC: Disposition of caspofungin: role of distribution in determining pharmacokinetics in plasma. Antimicrob Agents Chemother 2004, 48:815-823.

doi:10.1186/cc10455

Cite this article as: Roch et al: Effect of fluid loading during

hypovolaemic shock on caspofungin pharmacokinetic parameters in pig. Critical Care 2011 15:R219.

Submit your next manuscript to BioMed Central and take full advantage of:

- Convenient online submission

- Thorough peer review

- No space constraints or color figure charges

- Immediate publication on acceptance

- Inclusion in PubMed, CAS, Scopus and Google Scholar

- Research which is freely available for redistribution

Submit your manuscript at www.biomedcentral.com/submit
() Biomed Central 